Article

\title{
Content Analysis of Passengers' Perceptions of Airport Service Quality: The Case of Honolulu International Airport
}

\author{
Wonmi Bae and Junwook Chi *
}

Citation: Bae, Wonmi, and Junwook Chi. 2022. Content Analysis of Passengers' Perceptions of Airport Service Quality: The Case of Honolulu International Airport. Journal of Risk and Financial Management 15: 5. https://doi.org/ 10.3390/jrfm15010005

Academic Editor: Thanasis Stengos

Received: 24 November 2021

Accepted: 28 December 2021

Published: 30 December 2021

Publisher's Note: MDPI stays neutral with regard to jurisdictional claims in published maps and institutional affiliations.

Copyright: (C) 2021 by the authors. Licensee MDPI, Basel, Switzerland. This article is an open access article distributed under the terms and conditions of the Creative Commons Attribution (CC BY) license (https:// creativecommons.org/licenses/by/ $4.0 /)$.
School of Travel Industry Management, Shidler College of Business, University of Hawaii at Manoa, 2560 Campus Road, George Hall 346, Honolulu, HI 96822, USA; wonmi@hawaii.edu

* Correspondence: jwchi@hawaii.edu

\begin{abstract}
This paper explores passengers' perceptions toward airport service quality through a content analysis. Using 1341 review comments posted on the Skytrax website, we identify satisfiers, dissatisfiers, and performance factors that determine passengers' experiences at the Honolulu International Airport and the world's leading airports (Singapore Changi Airport, Haneda Airport, Incheon International Airport, Hamad International Airport, and Hong Kong International Airport). The results show that the Honolulu International Airport needs to improve cleanliness of the facilities, signage, and staff courtesy. A context-specific examination reveals that security, check, flight, line, and staff are the most frequently occurring words used by dissatisfied passengers. The most common words mentioned by satisfied users of the world's leading airports include staff, terminal, clean, time, immigration, and free. These findings provide suggestions and implications concerning customers' perspectives and may help airport managers enhance airport service quality and renovate airport facilities.
\end{abstract}

Keywords: airport service quality; content analysis; Honolulu international airport; sentiment analysis; text analytics technique

\section{Introduction}

Customer satisfaction and perceived value can determine destination image and market propensity and understanding passengers' perceptions of airport service quality is necessary for airport management and tourism development. Airports have become a dynamic space for enjoying shopping, experiencing leisure activities, and relaxing during a stop-over. Since tourism services begin and end at an airport, a commercially oriented and competitive airport is vital for tourism growth and destination competitiveness (Gupta and Venkaiah 2015; Wattanacharoensil et al. 2017). Satisfied passengers are more likely to spread positive word-of-mouth, contributing to traveler retention and destination loyalty (Della Corte et al. 2015; Prentice and Kadan 2019). Therefore, enhancing visitor satisfaction and destination image can produce economic benefits and competitive advantages for destinations.

To measure passenger satisfaction and airport service quality, various methods have been employed in the literature (e.g., Ching and Lau 2016; Eboli and Mazzulla 2009; Fodness and Murray 2007; Kurniawan et al. 2017; Maslen 2014; Pabedinskaitè and Akstinaitè 2014; Lupo 2015; Pantouvakis and Renzi 2016; Tsai et al. 2011). A growing body of research has recently used online reviews and content analysis tools to examine airport service quality and performance from the passenger's point of view. A number of studies have relied on Leximancer to analyze online reviews of airports (e.g., Zakrzewski 2008; Chuchu 2017; Brochado et al. 2019; Zhao 2019). Leximancer is a new technique that employs statistical algorithms to analyze natural language and organize text into sentiment terms. The benefits of using Leximancer software are that, based on word frequency and connectivity, it enables researchers to identify main concepts and discover linkage between each concept (Smith 
and Humphreys 2006). In addition, Leximancer is effective for a large volume of data so researchers can quickly determine and highlight the important concepts (Azeem et al. 2012). Other studies have used NVivo to analyze travelers' perceptions of airports (Caballero Galeote and Mestanza 2020). Unlike Leximancer's automatic content analysis, NVivo provides various functions for manipulating data records, coding, and performing text search queries. Nvivo is appropriate for a small volume of data, so it helps to focus on more specific words. With Nvivo, researchers are able to organize and categorize main concepts, so it is advantageous for determining important themes (Zakrzewski 2008). Therefore, it helps researchers extract ideas and link them with data to address specific research questions (Azeem et al. 2012). By using Leximancer, we can identify general main concept ideas and word connectivity, and by using Nvivo, we can verify more detailed information or words. Since Honolulu airport offers small sample numbers, combining Leximancer and Nvivo will help to enhance the reliability and accuracy of the study results.

The purpose of this paper is to further assess passengers' perceptions toward airport service quality using the airline passengers' online review and content analysis tools. This paper conducts an analysis of concept maps, word frequencies and trees, and service attribute ratings to evaluate customer sentiments. Data visualization reveals key factors influencing passengers' satisfaction and dissatisfaction with airport experiences.

Our study differs from previous studies in two aspects. First, we consider a case study of the Honolulu International Airport in comparison to the world's top five airports (Singapore Changi Airport, Haneda Airport, Incheon International Airport, Hamad International Airport, and Hong Kong International Airport). This approach allows direct comparisons of the crucial drivers for traveler experiences with the Honolulu International Airport and the leading global airports. The prevailing satisfiers and dissatisfiers are also compared using airport benchmarking of the world's top five airports (Skytrax 2018).

The Honolulu International Airport (HIA) is one of the 30 busiest airports in the United States. In 2018, over 20 million passengers used HIA, and the airport supported about 15,000 jobs and generated \$629 million in revenue (Hawaii Tourism Authority 2019). Despite the significant role of the airport in the Hawaiian tourism industry, HIA was rated only 2 out of 10 in terms of overall service quality (Skytrax 2018). According to U.S. News \& World Report (2019), a customer survey of airport users ranked HIA as the third worst among North American airports, with a satisfaction score of 719 out of 1000 points. Given the large gap between passenger expectations and actual services delivered at HIA, it is timely and necessary to perform a sentiment analysis of airport service quality to provide more useful information to the airport authority and help improve the tourism industry.

Another unique aspect of this paper is that we use both text analytics techniques and sentiment analysis to compare the results. Leximancer has several advantages over other content analysis tools. It is efficient for analyzing a large volume of data and appropriate for exploratory and predictive analytics (Smith and Humphreys 2006). The results are reliable as Leximancer automatically generates a list of important themes and concepts from the data without manual coding. This feature helps prevent researcher bias and subjectivity. However, Leximancer can produce unexpected or unexplained concepts and interrelationships, making it difficult to interpret results and draw conclusions (Sotiriadou et al. 2014). To treat this issue, we adopt NVivo text analysis software for an interpretive approach. NVivo requires manual data handling and is more suitable than Leximancer for a researcher-driven study. Researchers need to manage and organize data to interpret results appropriately.

Three research questions drive this study: (1) What are the most important themes and concepts associated with HIA and the world's leading airports? Using Leximancer's concept maps, we explore dominant themes and interrelationships among concepts. (2) What are the satisfiers, dissatisfiers, and performance factors that determine passengers' experiences at airports? Using NVivo's data visualization, we identify the most frequently mentioned words in positive and negative user review comments to analyze which airport service factors are essential to meet passengers' expectations (dissatisfiers) and which 
service elements serve to enhance passenger satisfaction (satisfiers). (3) What are the levels of air passengers' satisfaction and dissatisfaction with HIA compared to the world's leading airports? We compare and evaluate the average ratings of the airports using eight service attributes (queuing, time, terminal cleanliness, terminal seating, terminal sign, food and beverage, airport shopping, WI-FI, and airport staff).

The rest of the paper is organized as follows. The next section provides a review of the literature on customer surveys, interviews, and online reviews for the study of airport service quality. The content analysis and data used in this study are then discussed. The following section provides the results of content analysis, with special emphasis on the comparison of Leximancer and NVivo results. Finally, the last section presents important policy implications and limitations of this study.

\section{Literature Review}

\subsection{Traditional Customer Satisfaction Surveys and Interviews}

As airports become more competitive, it is imperative to investigate travelers' perceptions of airport service quality so airport managers can understand, meet, and exceed their customers' expectations. Customer surveys have been widely used to evaluate airport customer satisfaction and service quality. A large number of studies have investigated the importance of airport service quality by conducting surveys and suggested possible improvement proposals (Allen et al. 2020a, 2020b, 2021; Bellizzi et al. 2018; Ceccato and Masci 2017; Brida et al. 2016; Pandey 2016; Bezerra and Gomes 2015, 2016; Paramonovs and Ijevleva 2015; Jeon and Kim 2012; Liou et al. 2011). For example, Allen et al. (2021) investigated airport passengers' satisfaction to create practical strategies for airport services. Using passenger surveys from the Lamezia Terme international airport in Italy, they claimed that operators should focus on airport cleanliness to improve airport service quality. Allen et al. (2020b) employed a SEM approach to investigate airport service quality and found that environment (e.g., terminal cleanliness) and control (e.g., security) factors are the most significant dimensions that influence passengers' overall satisfaction. Bellizzi et al. (2018) conducted face-to-face interviews to evaluate passengers' satisfaction toward the Lamezia Terme airport's service quality and revealed that satisfaction factors and levels differ depending on travelers' backgrounds. Paramonovs and Ijevleva (2015) also employed a survey method to analyze major satisfaction factors for passengers at Riga International Airport in Latvia. Using 937 valid samples, the results indicated that telecommunications, effective signage, clean restrooms, staff courtesy, and availability are key factors affecting air passengers' satisfaction.

Similarly, Bezerra and Gomes (2015) focused on passenger characteristics and critical service factors that influence travelers' satisfaction with airports. Their study used surveys from departing passengers at the Guarulhos International Airport and found that perceived levels of service quality dimensions vary across travelers' characteristics. Liou et al. (2011) surveyed Taiwan International airport customers' satisfaction using the dominance-based rough set approach (DRSA). The results indicated that face-to-face contact, such as staff courtesy and security, is a significant factor affecting passenger satisfaction. Furthermore, Brida et al. (2016) examined the relationship between Information and Communication Technology services (ICTs) and airport customers' perception toward the Chile airport service quality. Based on the surveys with 995 participants, the study concluded that improving information and communication technologies would provide more positive experiences to passengers and improve airport service quality. Pandey (2016) assessed airport service quality at the Suvarnabhumi (BKK) and Don Mueang (DMK) airports in Thailand. The result showed that DMK airport needs to improve check-in and security lines, washroom cleanliness, and baggage claim area service, while BKK airport needs to enhance restaurant facilities.

In addition, Ghazi and Ammar (2018) studied air passengers' attitudes toward dutyfree shopping and airport food and beverage selections. They concluded that cognitive and affective evaluations could increase international visitors' satisfaction and positively affect 
their intentions to revisit and recommend the service. Ceccato and Masci (2017) explored the linkage between airport environments and passengers' perceived safety. Using 3859 passengers' responses, the results showed that a subpar airport environment, such as uncleanly bathrooms, limited dining options, and slow-moving security checkpoints, is more likely to elicit negative customer perceptions. Jeon and Kim (2012) studied the relationship between airport servicescape, emotional states, and behavioral intentions. They collected 300 samples from Incheon International Airport passengers, finding that functional, safety, esthetic, and social factors are related to positive emotions, while ambient and social factors are related to negative emotions.

\subsection{Social Networks and Other Online Reviews}

While traditional surveys and interviews are valuable sources of data, the contents of online reviews have been utilized in recent research to evaluate airport performance and service quality. Analyzing online reviews can be a cost- and time-efficient method to obtain customer perceptions and track recent service trends. It has been claimed that sentiment analysis of online reviews can identify newer insights into airport service quality than traditional techniques (Martin-Domingo et al. 2019). Because online reviews enable service providers to identify their customers' satisfaction and dissatisfaction levels, such customer feedback can be a useful resource for the tourism and hospitality industry (Schuckert et al. 2015). For example, Bogicevic et al. (2013) used a visual data mining technique to evaluate airport customer satisfaction and airport service quality. Their study used 1095 air passengers' reviews and applied the most frequently identified attributes to explore factors affecting airport customers' satisfaction and dissatisfaction. The results showed that a pleasant and clean environment is most often related to satisfaction, while security, signs, and poor restaurants are more frequently related to dissatisfaction.

Straker and Wrigley (2018) analyzed the top 100 airports' mission statements and digital channels to investigate the link between digital channel typologies and content needs. Their findings indicated that well-designed mission statements delivered through digital channels can increase customer satisfaction. Using 9632 passenger comments posted on Skytrax (2018) examined the relationship between customer satisfaction and various attribute ratings, such as seat comfort, staff, ground service, and entertainment. Their study reported that ground services including a lounge's physical environment, baggage claim, and ticketing experiences, are essential factors affecting air passengers' experiences and satisfaction.

A growing body of research has recently used content analysis tools to examine airport service quality and performance from the passenger's point of view. A number of studies have relied on Leximancer to analyze online reviews of airports (e.g., Brochado et al. 2019; Zhao 2019; Chuchu 2017; Zakrzewski 2008). Leximancer is a new technique that employs statistical algorithms to analyze natural language and organize text into sentiment terms. For instance, Brochado et al. (2019) used 1200 online reviews from TripAdvisor to explore travelers' experiences with air transport services. The results of Leximancer analysis showed that airport operations, such as check-in, baggage handling, and boarding gate, are major drivers of air passengers' overall satisfaction. Using review comments from Skytrax about Chinese airlines, Zhao (2019) examined passengers' perceptions of service quality and travelers' intention to recommend, finding that value for money is the crucial attribute for all types of passengers.

Other studies have used NVivo to analyze travelers' perceptions of airports (e.g., Caballero Galeote and Mestanza 2020; Wattanacharoensil et al. 2017; Azeem et al. 2012). Unlike Leximancer's automatic content analysis, NVivo provides various functions for manipulating data records, coding, and performing text search queries. Therefore, it helps researchers extract ideas and link them with data to address specific research questions. For example, Caballero Galeote and Mestanza (2020) studied the perceptions of both residents and international travelers toward services at the Málaga-Costa Del Sol Airport. The results of NVivo analysis suggested that residents and travelers have different points of view 
regarding negative externalities of the airport (e.g., pollution, noise, and mass tourism), revealing that international travelers exhibited almost no concerns about these issues. Wattanacharoensil et al. (2017) used NVivo to examine airport customer experiences in relation to their views of the destinations. Based on 732 reviews for 15 airports, they found that an airport is an important internal component of the tourism experience and can affect an air passenger's positive perceptions of a destination.

\section{Method}

A content analysis is suitable for qualitative research and trend analysis, and it can capture any type of text, video, or image. The main advantages of a content analysis are its ability to coordinate information from unorganized documents and its applicability to both qualitative and quantitative research (Aureli 2017; Hsieh and Shannon 2005). It effectively captures the characteristics and meanings behind the text of a message and identifies complex concepts that otherwise cannot be efficiently summarized.

\subsection{Leximancer and NVivo}

For comparison purposes, we use both text analytics techniques and sentiment analysis to identify crucial factors affecting traveler experiences from traveler reviews and comments. First, Leximancer is used to visually display major themes and concepts based on frequency of text. Each bubble in a concept map indicates a different theme. The larger the bubble, the more frequently that term or theme is mentioned in review texts. In terms of bubble color, warm colors (e.g., red or orange) denote more important and relevant themes, while cool colors (e.g., green or blue) imply less significant themes (Leximancer 2020). Bubble overlap indicates that those themes are related to each other and that reviewers frequently mention these words together. On the other hand, bubbles at a distance from each other imply that the themes are not correlated with each other. Leximancer automatically generates a ranked concept list based on relevance and word frequency.

Next, NVivo is employed to demonstrate the most frequently mentioned words for positive and negative comments. In this paper, the data are divided into two groups based on the reviewers' intention to recommend the airport. The word frequency analysis then identifies satisfiers, dissatisfiers, and performance factors that determine passengers experiences at airports. Matzler and Sauerwein (2002) claimed that performance factors can generate a high level of customer satisfaction when fulfilled but at the same time result in a high level of dissatisfaction when neglected. Thus, performance factors can appear in the words and phrases most frequently mentioned by both satisfied and dissatisfied travelers. NVivo creates word trees to demonstrate a branching view of frequently occurring words. Finally, we compare individual rating scores across eight airport attributes (queuing time, terminal cleanliness, terminal seating, terminal sign, food and beverage, airport shopping, WIFI, and airport staff). The null hypothesis for the equality of two mean values between HIA and the world's leading airports is tested to examine the levels of airport customer satisfaction.

\subsection{Skytrax Data}

This study uses review comments posted between 2004 and 2019 on Skytrax, the largest airport and airline review site with over 700 airports. Skytrax is a useful resource for researchers in analyzing air passengers' experiences and perspectives regarding airport and airline services (Wattanacharoensil et al. 2017) and offers a verification system to increase the validity of air passenger reviews. This paper describes a case study comparing HIA to a group of the world's leading airports. According to Skytrax (2018), Singapore Changi Airport, Haneda Airport, Incheon International Airport, Hamad International Airport, and Hong Kong International Airport received the highest overall scores and were voted the world's top five airports by international travelers. These airports are selected to identify the key service elements that achieve high passenger satisfaction. In this paper, we collect a total of 1341 usable review comments (139,560 words) and rating scores of service attributes 
of the HIA (72 reviews, 10,037 words), as well as the five comparable airports (1269 reviews, 129,523 words). Only English language reviews are collected. Table 1 shows the information from review comments used in the analysis.

Table 1. Information of the Honolulu International Airport and the World's Leading Airports.

\begin{tabular}{|c|c|c|c|c|c|}
\hline $\begin{array}{c}\text { Average Skytrax } \\
\text { Rating (2018) }\end{array}$ & Location & Airport Name (Code) & $\begin{array}{c}\text { Passengers } \\
\text { (Million, 2018) }\end{array}$ & $\begin{array}{l}\text { Number of } \\
\text { Reviews }\end{array}$ & $\begin{array}{l}\text { Number of } \\
\text { Words }\end{array}$ \\
\hline $2 / 10$ & United States & $\begin{array}{l}\text { Honolulu International Airport } \\
\text { (HNL) }\end{array}$ & 20.99 & 72 & 10,037 \\
\hline $7 / 10$ & Singapore & Singapore Changi Airport (SIN) & 65.60 & 375 & 35,826 \\
\hline $8 / 10$ & Japan & Haneda Airport (HND) & 87.13 & 62 & 7143 \\
\hline $6 / 10$ & South Korea & Incheon International Airport (ICN) & 68.26 & 241 & 25,080 \\
\hline $6 / 10$ & Qatar & Hamad International Airport (DOH) & 34.50 & 305 & 34.824 \\
\hline $6 / 10$ & Hong Kong & $\begin{array}{c}\text { Hong Kong International Airport } \\
\text { (HKG) }\end{array}$ & 74.70 & 286 & 26,650 \\
\hline
\end{tabular}

Sources: Traffic Statistics Changi Airport Group, Passenger traffic at Tokyo Airport 2018, Maeil Business News, Business Traveller, Hongkong Business, and Hawaii Tourism Authority.

Review titles, comments, recommendations, dates, locations, attribute ratings, and overall ratings are collected in MS-Excel spreadsheet format. Table 2 shows reviewer information for the entire sample by type of passengers, experience at the airport, review year, satisfaction rating, and recommendation. Types of passengers identified by reviewers included 165 business travelers; 139 couple leisure travelers; 165 family leisure; and 262 solo travelers. Reviewer reports of their airport experience fell into these categories: 261 travelers who experienced both arrival and departure; 92 who arrived only; 157 who departed only; and 221 who experienced transit only. It should be noted that the type of travel and airport experience data have been available only since June 2015. With respect to overall satisfaction ratings (on a scale from 1 to 10), there are significant differences between HIA and the world's leading airports. For HIA, 58\% (42 reviewers) selected ratings of 1 or 2 (poor), while only $11 \%$ (149 reviewers) selected the same low ratings for the world's top five airports. The largest number of respondents (468 reviewers) chose ratings of 9 or 10 for the world's top five airports. In terms of recommendations, the majority of reviewers (67 of 72 records, or a whopping $93 \%$ ) would not recommend HIA to others. In contrast, 731 passengers $(56 \%)$ intended to recommend one of the world's five leading airports.

Table 2. Information of the Airport Reviews.

\begin{tabular}{ccccc}
\hline Category & Details & $\begin{array}{c}\text { Number of Reviews } \\
\text { (HNL) }\end{array}$ & $\begin{array}{c}\text { Number of Reviews (SIN, } \\
\text { HND, ICN, DOH, HKG) }\end{array}$ & Total \\
\hline \multirow{3}{*}{ Review year } & $2004-2008$ & $11(52.4 \%)$ & $10(47.6 \%)$ & 21 \\
& $2009-2014$ & $18(3.3 \%)$ & $533(96.7 \%)$ & 751 \\
& $2015-2019$ & $43(5.6 \%)$ & $159(96.4 \%)$ & 769 \\
\hline \multirow{2}{*}{ Type of travelers } & Business & $6(3.6 \%)$ & $117(84.2 \%)$ & 165 \\
& Couple leisure & $22(15.8 \%)$ & $160(97.0 \%)$ & 139 \\
& Family leisure & $5(3.0 \%)$ & $252(96.2 \%)$ & 262 \\
\hline \multirow{5}{*}{ Experience at airport } & Solo leisure & $10(3.8 \%)$ & $242(92.7 \%)$ & 261 \\
& Arrival and departure & $19(7.3 \%)$ & $90(97.8 \%)$ & $137(87.3 \%)$ \\
& Arrival only & $2(2.2 \%)$ & $219(99.1 \%)$ \\
\hline
\end{tabular}


Table 2. Cont.

\begin{tabular}{ccccc}
\hline Category & Details & $\begin{array}{c}\text { Number of Reviews } \\
\text { (HNL) }\end{array}$ & $\begin{array}{c}\text { Number of Reviews (SIN, } \\
\text { HND, ICN, DOH, HKG) }\end{array}$ \\
\hline & Rating 1-2 & $42(22.0 \%)$ & $149(78.0 \%)$ & Total \\
& Rating 3-4 & $20(8.7 \%)$ & $209(91.3 \%)$ & 191 \\
Overall satisfaction & Rating 5-6 & $1(0.4 \%)$ & $243(99.6 \%)$ & 229 \\
& Rating 7-8 & $3(1.6 \%)$ & $186(98.4 \%)$ & 189 \\
& Rating 9-10 & $1(0.2 \%)$ & $468(99.8 \%)$ & 469 \\
\hline \multirow{2}{*}{ Recommendation } & Yes & $5(0.7 \%)$ & $731(99.3 \%)$ & 736 \\
\hline
\end{tabular}

\section{Results}

\subsection{Themes and Concepts}

Using word frequency and co-occurrence counts, we identify themes and concepts, demonstrating how these words are related to each other. Figure 1 illustrates the themes and concepts in the passengers' reviews for HIA. The overall satisfaction is rated based on a 1-10 rating scale. The concept maps display nine dominant themes: flight, airport, security, line, signage, departure, arrived, baggage, and check. The most important themeflight - is related to the concepts of time, hour, terminal, gate, international, and shuttle. The second most import theme-airport-is related to the concepts of signage, worst, and place. Selecting the airport concept prompted Leximancer to automatically generate a list of related words and terms used by customers. The related word-like concepts included terms such as hours, signage, line, shuttle, and worst, indicating that customers frequently mentioned these words together with the word airport when they wrote comments on the airport services. The next important theme-security-is related to the concepts of better, staff, customs, gate, and long.

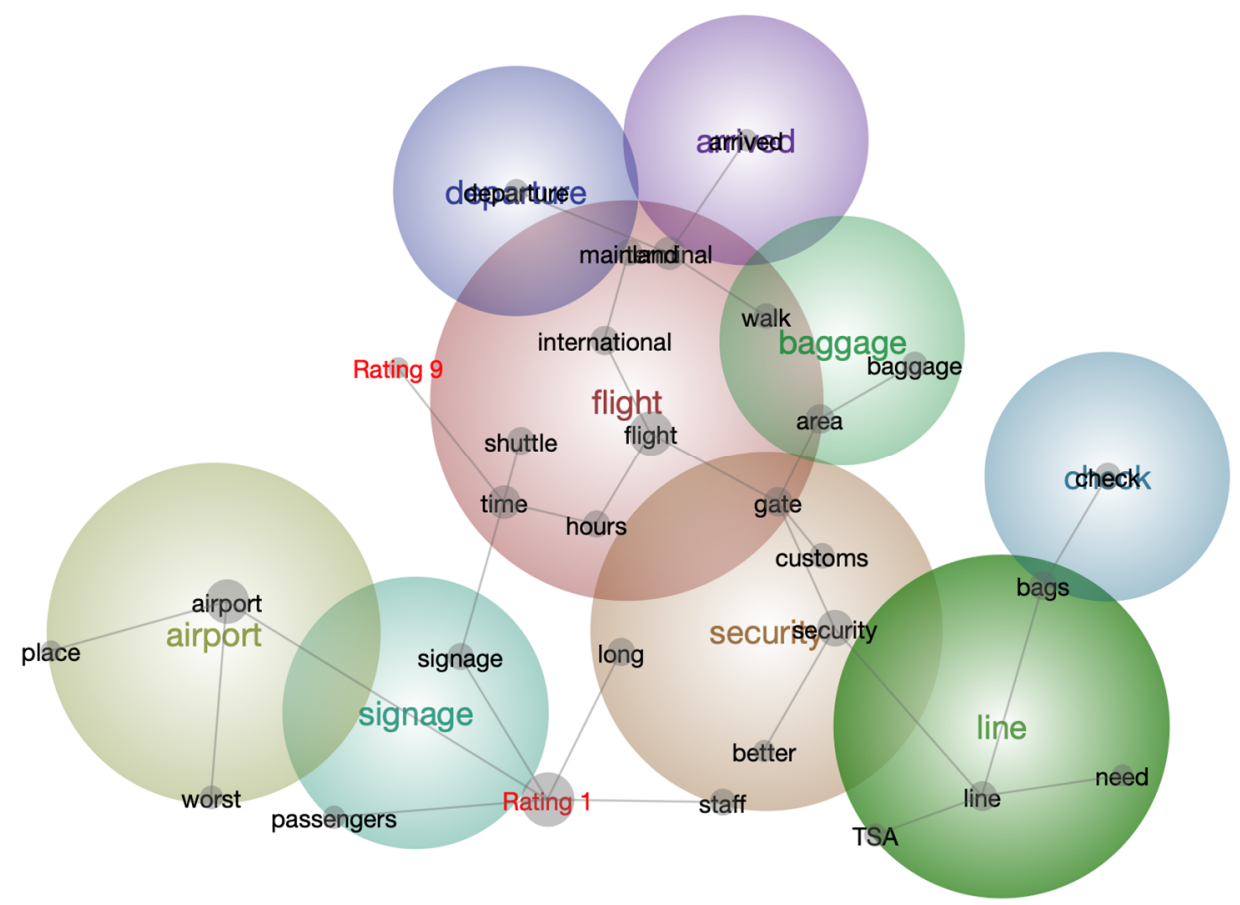

Figure 1. Concept Maps and Overall Ratings for the Honolulu International Airport.

In terms of overall satisfaction levels, the bubble containing the rating 1 (not recommended) is closely located between the signage and security themes, indicating that some passengers had unsatisfactory experiences with signs and security at the airport. These 
results are consistent with Fodness and Murray's (2007) findings showing that terminal signs are an important element of airport service quality. Rating 1 is also associated with other concepts such as line, bags, long, and check. Some negative comments are related to these concepts as follows:

"This is a horrible airport. It is disorganized and lacks signage. [..] Security is just rude-my guy was quite thrilled when he found my oversized container of sun spray. I won't be back soon". (July 2019, Business, United States)

"This airport was the worst part of our trip to Hawaii. [ . . ] As others have noted, indoor signage is poor. Amenities such as shopping, are limited. [ . . ]. And no working wifi. [ ... ] I dreaded every minute at this airport". (November 2017, Couple leisure, United States)

On the contrary, the bubble containing the rating 9 (recommended) is positioned near the flight theme and connected to the concepts of time, shuttle, hours, international, gate, and area. These findings imply that on-time shuttle services help increase passengers' satisfaction levels. For example, some satisfied passengers posted relevant comments as follows:

"We arrived at Honolulu airport from [ . . ] On arrival [ . . ]. On leaving the airport our prearranged shuttle was exactly where we were told it would be and we were on our way in no time. On departure to NYC we once again got through the airport quickly and easily. [ ... ]. you will find your experience at Honolulu airport as pleasant as ours was". (April 2018, Couple leisure, Australia)

Turning our attention to the world's top five airports (Figure 2), concept maps featured eight themes: airport, time, gate, hour, luggage, queue, clean, and duty-free. The most important theme-airport - is related to the concepts of best, world, excellent, fast, and service. The next important theme-gate-is associated with transit, better, lounge, and area. The themehour - is related to long, line, and open. Regarding the overall satisfaction levels, the rating 1 bubble is located between the queue and hour themes, while the rating 10 bubble is found among the concepts of clean, friendly, excellent, and efficient.

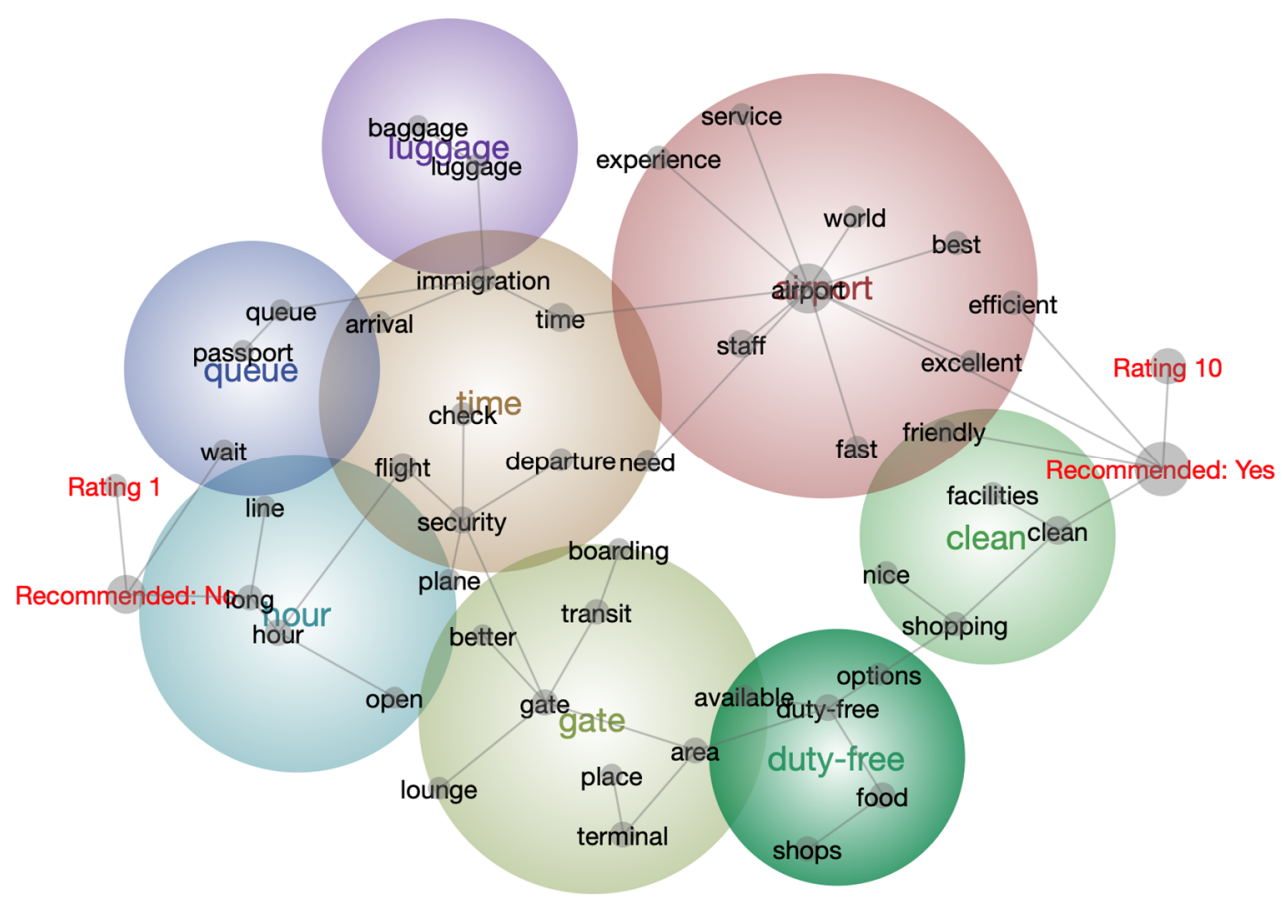

Figure 2. Concept Maps and Overall Ratings for the World's Leading Airports.

Some passengers' comments include unfavorable sentiments: 
"Seoul Incheon is the worst airport ever. [ ... ] Long lines in all counters [..] Ridiculously long lines in baggage check and immigration [ ... ] And, when you come back-surpriseanother long waiting line for immigration check. From the moment you leave the plane till you finally get out of the airport it can be easily 2 hours [ . . ] Good joke. " (May 2016, Solo leisure, South Korea)

In contrast, some reviewers recognize favorable sentiments as follows:

"Tokyo Haneda Airport was one of the most efficient and relaxing experiences in an airport in my life! Everything was fast and highly efficient. The airport design is really nice being open and easy to navigate. [ . . . ] definitely choose Haneda on my next trip to Tokyo!" (February 2017, Solo leisure, Australia)

"The cleanliness of Incheon Airport is very clear and [ ... ] The workers are also very friendly and have robots that match the names of high-tech airports. We will also look forward to the second passenger terminal, which will open in February." (January 2018, Family leisure, South Korea)

"Doha Hamad Airport is for me the best experience I could have in an airport. Clean, Comfortable, many seats, new with a dynamic and modern design. [ . . . Nothing else comparable. " (January 2018, Business, Qatar)

\subsection{Frequent Words and Word Trees}

The review data are further examined to identify the most frequently mentioned words for two groups—satisfied and dissatisfied passengers-based on their intentions to recommend the airport. Table 3 shows the word frequencies for satisfied and dissatisfied passengers with HIA. It should be noted that words irrelevant to the analysis (e.g., the name of the airport) are excluded from the frequently occurring words.

Table 3. Frequently Occurring Words for the Honolulu International Airport.

\begin{tabular}{|c|c|c|c|c|c|c|c|}
\hline \multicolumn{4}{|c|}{ Frequent Words for Satisfied Travelers } & \multicolumn{4}{|c|}{ Frequent Words for Dissatisfied Travelers } \\
\hline Word & Length & Count & $\begin{array}{c}\text { Weighted } \\
\text { Percentage }(\%)\end{array}$ & Word & Length & Count & $\begin{array}{c}\text { Weighted } \\
\text { Percentage }(\%)\end{array}$ \\
\hline time & 4 & 6 & 1.65 & security & 8 & 59 & 1.23 \\
\hline flight & 6 & 4 & 1.10 & check & 5 & 46 & 0.96 \\
\hline terminal & 8 & 4 & 1.10 & flight & 6 & 40 & 0.84 \\
\hline airlines & 8 & 3 & 0.82 & line & 4 & 34 & 0.71 \\
\hline area & 4 & 3 & 0.82 & staff & 5 & 33 & 0.69 \\
\hline arrival & 7 & 3 & 0.82 & terminal & 8 & 32 & 0.67 \\
\hline customs & 7 & 3 & 0.82 & time & 4 & 28 & 0.59 \\
\hline far & 3 & 3 & 0.82 & gate & 4 & 26 & 0.54 \\
\hline gates & 5 & 3 & 0.82 & international & 13 & 24 & 0.50 \\
\hline like & 4 & 3 & 0.82 & long & 4 & 24 & 0.50 \\
\hline
\end{tabular}

The most frequent words associated with satisfied passengers (satisfiers) are time, flight, terminal, airlines, and area. Dissatisfied passengers use different keywords and phrases (dissatisfiers), such as security, check, flight, line, and staff. The most frequently occurring phrases for dissatisfied passengers are represented by security (59 counts) and check (46 counts), as demonstrated in Table 3. It is found that security, terminal, flight, staff, and line are recognized as the performance factors that determine passengers' experiences at HIA.. As found in the following comments, the security check is frequently mentioned by HIA users:

"Then we were ushered back outside into a pre-security line that didn't move for 30 minutes because they didn't have enough staff available! By this point our flight was about to board!". (September 2017, Couple leisure, United States)

"The check in area at the inter-island terminal is a mess with 2 security check points both for mainland and international flights. So if your on a Hawaiian flight you must stay in 
the queue which ends outside the door of the terminal at peak times with no signage. " (October 2007, Unidentified traveler)

A similar text analysis is carried out to identify frequently occurring words for the world's top five airports (Table 4). The most frequently occurring words for dissatisfied passengers include terminal (266 counts), immigration (246 counts), security (245 counts), staff (239 counts), long (225 counts), and time (225 counts). On the other hand, the frequent occurring words for satisfied passengers include staff (336 counts), terminal (335 counts), clean (331 counts), time (329 counts), immigration (289 counts), and free ( 284 counts). The words terminal, immigration, staff, and time have been recognized as the performance factors that significantly affect passengers' satisfaction and dissatisfaction with the world's leading airports. A large number of comments include these performance factors:

Table 4. Frequently Occurring Words for the World's Leading Airports.

\begin{tabular}{|c|c|c|c|c|c|c|c|}
\hline \multicolumn{4}{|c|}{ Frequent Words for Satisfied Travelers } & \multicolumn{4}{|c|}{ Frequent Words for Dissatisfied Travelers } \\
\hline Word & Length & Count & $\begin{array}{c}\text { Weighted } \\
\text { Percentage }(\%)\end{array}$ & Word & Length & Count & $\begin{array}{c}\text { Weighted } \\
\text { Percentage }(\%)\end{array}$ \\
\hline staff & 5 & 336 & 0.87 & terminal & 8 & 266 & 0.88 \\
\hline terminal & 8 & 335 & 0.87 & immigration & 11 & 246 & 0.81 \\
\hline clean & 5 & 331 & 0.86 & security & 8 & 245 & 0.81 \\
\hline time & 4 & 329 & 0.85 & staff & 5 & 239 & 0.79 \\
\hline immigration & 11 & 289 & 0.75 & long & 4 & 225 & 0.74 \\
\hline free & 4 & 284 & 0.74 & time & 4 & 225 & 0.74 \\
\hline good & 4 & 268 & 0.69 & transit & 7 & 216 & 0.71 \\
\hline security & 8 & 266 & 0.69 & flight & 6 & 196 & 0.65 \\
\hline flight & 6 & 260 & 0.67 & check & 5 & 173 & 0.57 \\
\hline food & 4 & 240 & 0.62 & passengers & 10 & 164 & 0.54 \\
\hline
\end{tabular}

"Super amazing airport. Staff on the ground are very courteous. Entertainment is endless and for free!!! Best toilets, best restaurants, absolutely wow on everything!" (September 2018, Solo leisure, United Kingdom)

"Horribly overpriced, the most expensive airport I have been at. Rude staff and limited food options. Wifi hardly works and takes too long to log in. Really makes you not want to fly Qatar air just to avoid a stop over here." (August 2019, Couple leisure, Australia)

NVivo's word tree displays a branching view of the results showing the various contexts in which a frequently mentioned word occurs. For this study, we choose the most frequently occurring words for satisfied and dissatisfied passengers. Figure 3 displays word trees for time for satisfied HIA passengers and security for dissatisfied HIA passengers. The word tree security, for example, is related to long and slow security check and no signage at HIA.

Similarly, word trees display the words used most frequently by passengers at the world's leading airports (Figure 4). The word trees for staff and terminal demonstrate recurring phrases that surround the frequently occurring words. Satisfied passengers frequently mentioned friendly and helpful staff at the airports. The word terminal is frequently used by both satisfied and dissatisfied passengers. The word tree for terminal often shows relationships with an inconvenient terminal location and long, crowded transit to the concourse terminal. 

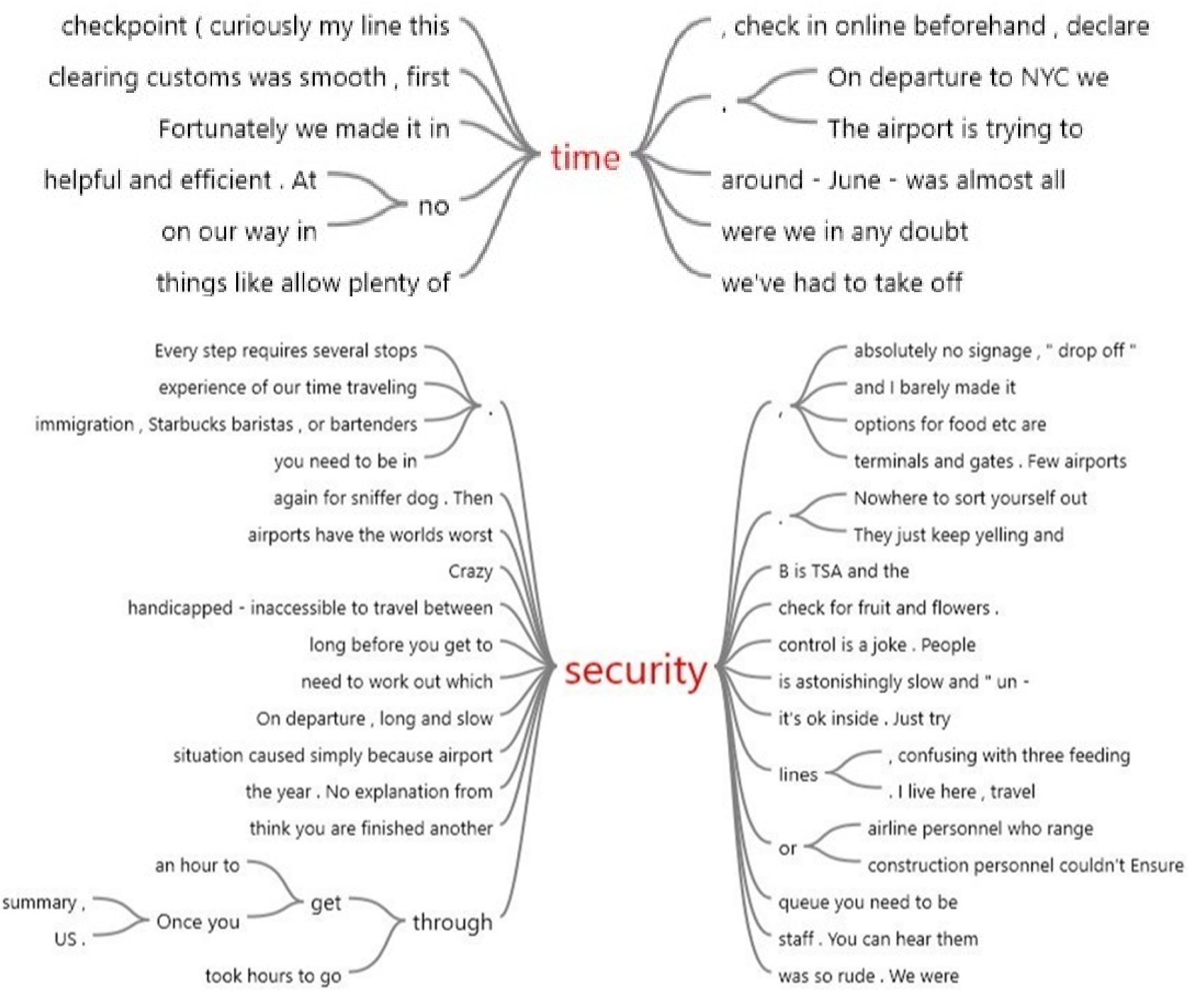

Figure 3. Word Trees "Time" and "Security" for the Honolulu International Airport.

Note that Skytrax has a relatively small sample size for HIA and small sample sizes may skew data by making rare occurrences more common than they actually are. To address this issue, we collect additional passengers' reviews for HIA from Yelp, posted between 2006 and 2019 (2286 reviews, 273,614 words) and conduct a content analysis for HIA (see Appendix A). In this paper, we use the overall rating scores of 1-2 and 4-5 to identify dissatisfied and satisfied passengers, respectively. The results including the Yelp data show that the most frequent words associated with satisfied passengers are flight, time, terminal, and open. On the other hand, the most frequent words associated with dissatisfied passengers are check, terminal, people, and security. These findings are generally consistent with the results of the content analysis using the Skytrax data, suggesting that there is no significant small-sample bias derived from the analysis. 


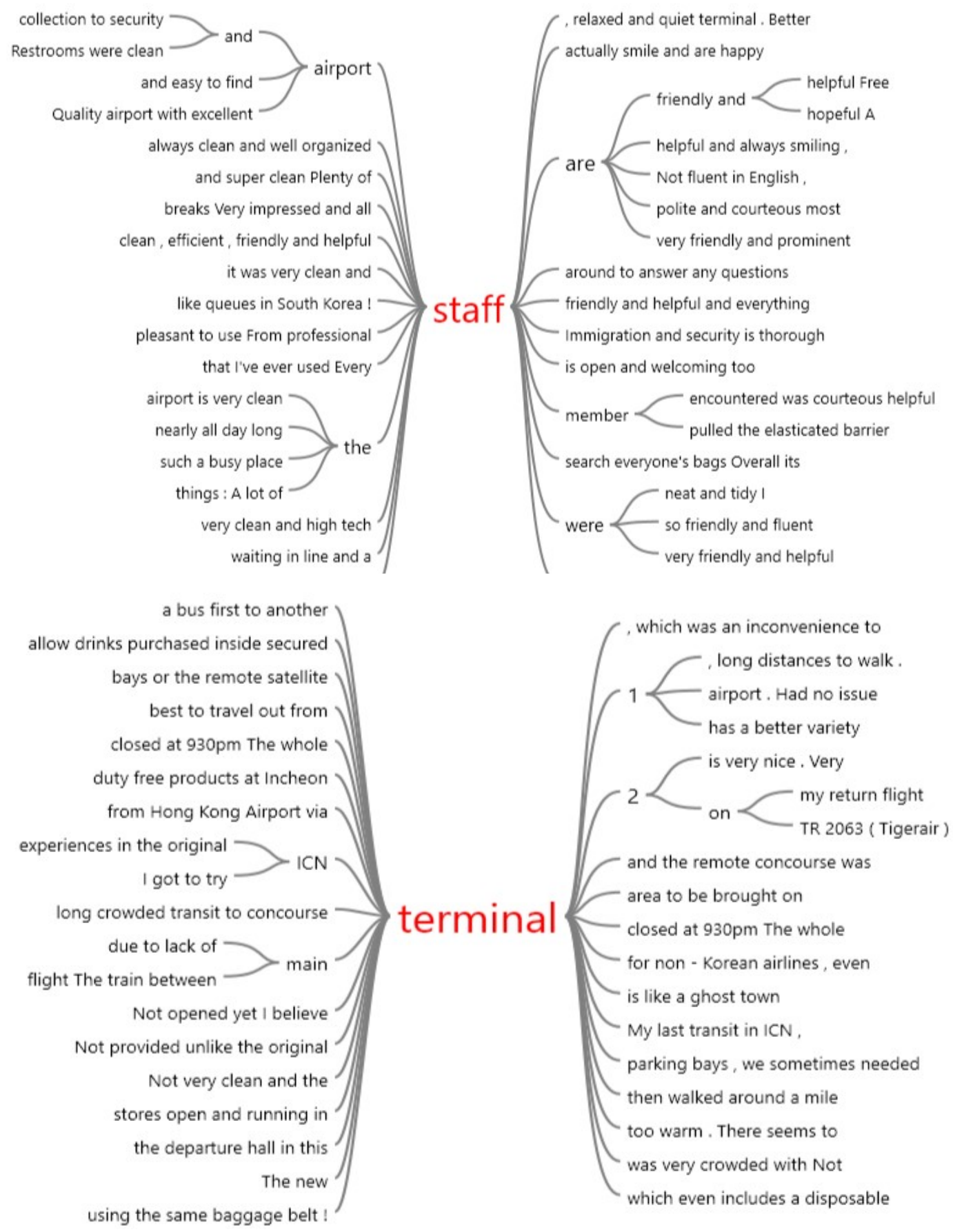

Figure 4. Word Trees "Staff" and "Terminal" for the World's Leading Airports.

\subsection{Attribute Ratings}

To measure customer satisfaction levels, the mean scores of eight attribute ratings are compared. Table 5 provides the average scores of HIA and the world's leading airports. These attribute ratings are based on a 1 -5 rating scale and directly expressed by passengers. In all cases, HIA exhibits lower mean scores compared to the scores of the world's most favorable airports. T-values for the equal means between HIA and the global leading airports are statistically significant at the $5 \%$ significance level. For HIA, airport staff (1.68) receives the lowest rating; terminal sign (1.69) is the second-lowest; and queuing time (1.86) is tied with WIFI (1.86) for the third-lowest. 
Table 5. Attribute Ratings of the Honolulu International Airport and the World's Leading Airports.

\begin{tabular}{|c|c|c|c|c|c|c|c|c|}
\hline $\begin{array}{l}\text { Airport } \\
\text { Code }\end{array}$ & $\begin{array}{l}\text { Queuing } \\
\text { Time }\end{array}$ & $\begin{array}{c}\text { Terminal } \\
\text { Cleanliness }\end{array}$ & $\begin{array}{l}\text { Terminal } \\
\text { Seating }\end{array}$ & $\begin{array}{c}\text { Terminal } \\
\text { Sign }\end{array}$ & $\begin{array}{l}\text { Food and } \\
\text { Beverage }\end{array}$ & $\begin{array}{c}\text { Airport } \\
\text { Shopping }\end{array}$ & WIFI & $\begin{array}{c}\text { Airport } \\
\text { Staff }\end{array}$ \\
\hline HNL & 1.86 & 2.21 & 2.13 & 1.69 & 2.09 & 2.11 & 1.86 & 1.68 \\
\hline $\begin{array}{l}\text { Average of the } \\
\text { five airports }\end{array}$ & 3.66 & 4.50 & 4.00 & 4.17 & 3.68 & 3.99 & 4.05 & 3.70 \\
\hline SIN & 4.13 & 4.72 & 4.31 & 4.48 & 4.20 & 4.50 & 4.03 & 3.99 \\
\hline HND & 4.10 & 4.85 & 4.32 & 4.57 & 4.00 & 4.18 & 4.67 & 4.52 \\
\hline $\mathrm{ICN}$ & 3.28 & 4.48 & 3.63 & 3.71 & 3.02 & 3.94 & 3.82 & 2.98 \\
\hline $\mathrm{DOH}$ & 3.04 & 4.07 & 3.81 & 3.78 & 3.46 & 3.27 & 3.48 & 3.35 \\
\hline $\mathrm{HKG}$ & 3.75 & 4.39 & 3.95 & 4.30 & 3.73 & 4.08 & 4.23 & 3.65 \\
\hline
\end{tabular}

Notes: T-values for the equal means between HIA and the top 5 airports are 8.67 for queuing time, 17.59 for terminal cleanliness; 9.43 for terminal seating; 12.92 for terminal sign; 6.78 for food and beverage; 10.14 for airport shopping; 7.28 for WIFI; and 7.90 for airport staff.

Among the eight attributes, terminal cleanliness (2.21) and terminal seating (2.13) achieve relatively higher satisfaction ratings. These outcomes indicate that possible improvements are required to increase overall airport service quality, primarily focusing on airport signs, staff, queuing times, and WIFI. Among the attribute ratings of the world's leading airports, terminal cleanliness (4.50) receives the highest score, terminal sign (4.17) is the second-highest, and WIFI (4.05) is the third-highest score in terms of airport customer satisfaction. The largest average difference between HIA and the world's leading airports is in the area of terminal signs, with HIA's score of 1.69 being 2.48 less than the average airport score of 4.17. The second-largest difference in attributes occurs in terms of terminal cleanliness. These two factors represent the largest areas for discrepancies (terminal sign and terminal cleanliness) between HIA and the world's leading airports, suggesting possible areas for significant improvements at HIA.

\subsection{Discussion of Results}

Both Leximancer and NVivo identify keywords for satisfied and dissatisfied passengers, and their results appear to be generally consistent. For HIA, Leximancer results show that passengers are satisfied with the flight theme, which is connected to the concepts of time, shuttle, hours, international, gate, and area. NVivo results also indicate that words most frequently mentioned by passengers are time, flight, gate, international, and area. Among dissatisfied passengers, both Leximancer and NVivo show the same key dissatisfying comments related to signage, security, staff, gate, and long.

Signage is one of the key dissatisfaction factors for HIA. Unclear or missing airport signs (e.g., baggage claim area and gate signs) may result in people getting lost, missing their flights, and wasting their time at the airport. Previous studies suggested that airport signs influence customer satisfaction (Fodness and Murray 2007; Moon et al. 2017; Pantouvakis and Renzi 2016). For example, Moon et al. (2017) considered that layout accessibility, such as clear airport signage, can reinforce customers' satisfaction. Additionally, Pantouvakis and Renzi (2016) discovered three essential dimensions for estimating airport service quality: signage, servicescape, and service. Therefore, it is logical to suggest that signage at HIA should be upgraded to prevent confusion and improve customer satisfaction.

For the world's top five airports, Leximancer and NVivo display long, wait, and hours as keywords for dissatisfied passengers. We also identify key enhancers of passenger satisfaction. The common words clean, facilities, excellent, efficient, staff, and shopping are shown as satisfaction factors in the results of both Leximancer and NVivo. This study confirms that the cleanliness of the terminal environment is an important factor in increasing passenger satisfaction. Elias Gonçalves and Caetano (2017) found that the cleanliness of airport facilities is related to air passengers' comfort dimension. Oh and Park (2014) also indicated that facility cleanliness is associated with airport image as well as airport selection. According to the Airports Council International, many airport users are sensitive to the 
cleanliness of environments like bathroom facilities. Restroom cleanliness and maintenance can be essential factors affecting passenger experiences and can encourage them to visit the airport again.

While shopping is revealed as a key satisfier for the world's leading airports, passengers rarely mention their shopping experiences at HIA. Our results show that the users of the world's top five airports give high satisfaction ratings to duty-free shops. Consistent with previous research (Bogicevic et al. 2013; Ghazi and Ammar 2018; Moon et al. 2017), dutyfree facilities and services can enhance international visitors' satisfaction and attitudes toward an airport. According to the Hawaii Tourism Authority (2019), Chinese, Korean, and Japanese visitors spend notably higher amounts of money than the average shoppers visiting from North America. In 2018, tourists from Japan, South Korea, and China spent $\$ 66, \$ 79$, and $\$ 115$ per person per day on shopping, respectively. Meanwhile, visitors from Canada, the U.S. West, and the U.S. East spent $\$ 14, \$ 17$, and $\$ 19$ per person per day, respectively (Hawaii Tourism Authority 2019). Enhancing duty-free selections may increase visitors' satisfaction as well as the airport's commercial revenues.

Our results also indicate that while staff is one of the satisfaction factors for the world's top five airports, it is a crucial dissatisfaction factor for HIA. Fodness and Murray (2007) claimed that staff courtesy helps improve airport service quality. Elias Gonçalves and Caetano (2017) also highlighted the importance of security staff in terms of overall customer satisfaction. Well-trained staff could help to increase the airport's efficiency and productivity (Pantouvakis and Renzi 2016).

\section{Conclusions}

The contribution of this paper is to conduct a content analysis using the case of HIA in comparison to the world's leading airports. Since no previous study has explored online reviews about HIA's service quality, the findings of this paper help improve understandings about air passengers' perspectives using actual airport customer feedback. Qualitative analysis identifies key drivers of satisfaction and dissatisfaction with airport services of the world's leading airports compared to HIA. The key findings and implications of the paper are as follows.

First, examination of the attribute ratings indicates that the mean scores of the world's leading airports' eight attribute ratings were significantly higher than HIA's average scores. Specifically, airport cleanliness and facilities (e.g., duty-free shops) are significant factors that influence air passengers' satisfaction at the five major airports and encourage customers to write positive reviews. A content analysis revealed that terminal, immigration, staff, and time are key performance factors that determine passengers' experiences at the world's leading airports. Meanwhile, long lines, security processes, queuing times, and flight delays are closely related to customer dissatisfaction at at HIA. Our results suggest that security check, immigration process, signage, and staff courtesy should be improved at HIA.

Second, we find that Leximancer and NVivo work in different ways. Leximancer determines the number of themes and concepts and identifies their interrelationships without the need for researcher input (Richards and Richards 1994). The easy-to-implement method does not require manual coding and data management, helping to reduce researcher bias and subjectivity (Sotiriadou et al. 2014). However, the first run of Leximancer did not produce sufficient information to draw conclusions from this study. For example, Leximancer's concept map automatically identified only two themes (signage and security) and a few concepts related to dissatisfied HIA users. On the other hand, the results of NVivo further revealed that time and security are also related to dissatisfaction. NVivo required manual handling of data, but it was more suitable than Leximancer to help us identify satisfiers, dissatisfiers, and performance factors. In this research, general concepts were collected from Leximancer and more detailed concepts were obtained from NVivo to improve accuracy and reliability. Our findings suggest that a combination of automatic 
and manual analyses could provide more reliable data interpretations and an in-depth understanding of satisfying and dissatisfying factors.

Finally, our results offer theoretical and practical contributions. Rahim (2016) and Yunus et al. (2013) proposed a conceptual framework using the interrelationships between service quality dimensions, passenger satisfaction, and customer loyalty. Their findings supported that perceived service quality can affect both passenger satisfaction and loyalty. Our results help improve understanding of satisfiers and dissatisfiers to enhance customer satisfaction and loyalty. Additionally, our findings provide practical managerial implications to the Airports Division of Hawaii Department of Transportation. For example, the content analysis results showed that signage, airport cleanliness, duty-free shopping, and airport staff seem to be key areas in which HIA can make improvements to achieve higher customer satisfaction. Based on actual passengers' reviews, this paper presents valuable information about the world's leading airport service quality benchmark and helps airport management teams develop appropriate airport operation strategies to meet customers' needs and wants. HIA is currently undergoing major renovations as part of the statewide Hawaii Airports Modernization Program and the improvements will include a new commuter terminal, the new Mauka concourse, a consolidated rental car facility, and pedestrian bridge replacement. Our findings provide important managerial implications for the airport management teams regarding airport service improvements and facility renovations.

We acknowledge several limitations of this study. First, since this paper used online reviews from Skytrax, we are unable to analyze passenger profile variables, such as age, gender, and nationality. To treat this issue, future studies may use both online reviews and traditional surveys to further analyze passenger satisfaction. Second, we collected English language reviews only, which are unlikely to reflect international perspectives from non-English speaking travelers. In the case of Hawaii tourism, it is crucial to include non-English reviews to capture the diverse perceptions of visitors from Asian countries. For example, future research could expand to include review comments in various languages to analyze the nuances associated with the language and understand travelers' perceptions by country. Third, a limited number of reviews were available for HIA and the entire Skytrax attribute rating system was not consistent from 2004 to 2019. Although Skytrax provided specific attribute ratings to measure airport service qualities, some attribute ratings (e.g., terminal seating, WIFI, and airport staff) have been available only since 2015. To address this issue, future studies should collect larger samples from various sources (e.g., Google, Yelp, TripAdvisor, Twitter, Instagram, and other social media channels) and identify deeper aspects of customer preferences and expectations as they change over time. Lastly, as airports face the unprecedented challenges and risks of the COVID-19 pandemic, future research should analyze the impact of the COVID-19 on air passengers' perceptions toward airport service regarding health and safety levels within the airport environment.

Author Contributions: Conceptualization, W.B. and J.C.; methodology, W.B. and J.C.; software, W.B.; visualization, W.B.; formal analysis, W.B. and J.C.; investigation, J.C.; writing-original draft prep, W.B. and J.C.; writing-review and editing, J.C. All authors have read and agreed to the published version of the manuscript.

Funding: This research received no external funding.

Institutional Review Board Statement: Not applicable.

Informed Consent Statement: Not applicable.

Data Availability Statement: Publicly available datasets were analyzed in this study. This data can be found here https: / www.airlinequality.com (accessed on 15 October 2021).

Conflicts of Interest: The authors declare no conflict of interest. 


\section{Appendix A. Frequently Occurring Words and Word Trees for HIA Including the Yelp Data (2006-2019)}

Table A1. Frequently Occurring Words for the Honolulu International Airport.

\begin{tabular}{|c|c|c|c|c|c|c|c|}
\hline \multicolumn{4}{|c|}{ Frequent Words for Satisfied Travelers } & \multicolumn{4}{|c|}{ Frequent Words for Dissatisfied Travelers } \\
\hline Word & Length & Count & $\begin{array}{c}\text { Weighted } \\
\text { Percentage (\%) }\end{array}$ & Word & Length & Count & $\begin{array}{c}\text { Weighted } \\
\text { Percentage }(\%)\end{array}$ \\
\hline time & 4 & 233 & 0.82 & people & 6 & 422 & 0.84 \\
\hline open & 4 & 191 & 0.67 & check & 5 & 367 & 0.73 \\
\hline security & 8 & 182 & 0.64 & security & 8 & 357 & 0.71 \\
\hline flight & 6 & 175 & 0.61 & time & 4 & 325 & 0.65 \\
\hline nice & 4 & 173 & 0.61 & TSA & 3 & 314 & 0.63 \\
\hline terminal & 8 & 168 & 0.59 & terminal & 8 & 301 & 0.60 \\
\hline people & 6 & 164 & 0.58 & food & 4 & 272 & 0.54 \\
\hline honolulu & 8 & 163 & 0.57 & long & 4 & 242 & 0.48 \\
\hline easy & 4 & 161 & 0.56 & international & 13 & 226 & 0.45 \\
\hline food & 4 & 159 & 0.56 & walk & 4 & 215 & 0.43 \\
\hline
\end{tabular}

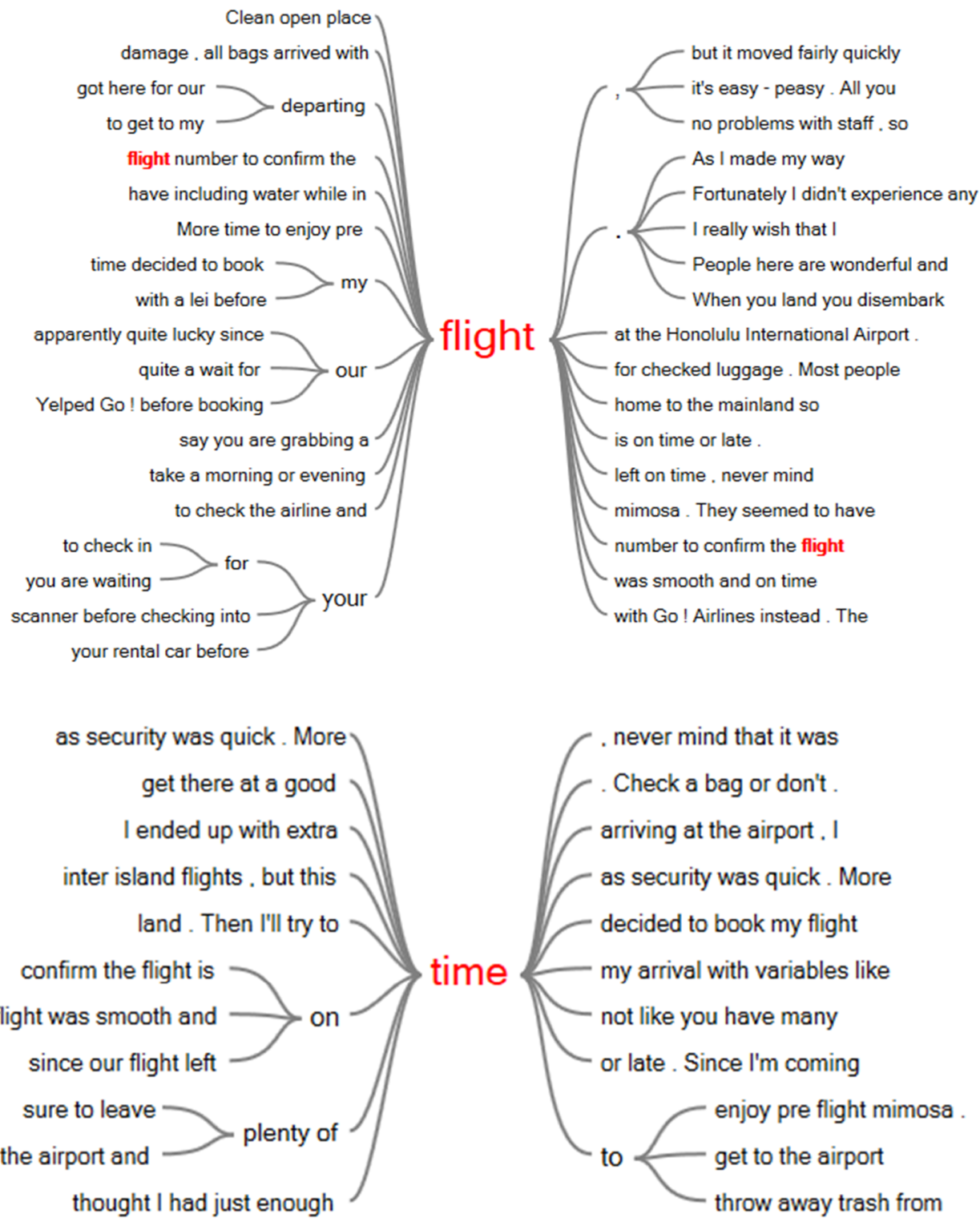

Figure A1. Word Trees "Flight" and "Time" for Satisfied Travelers at HIA. 

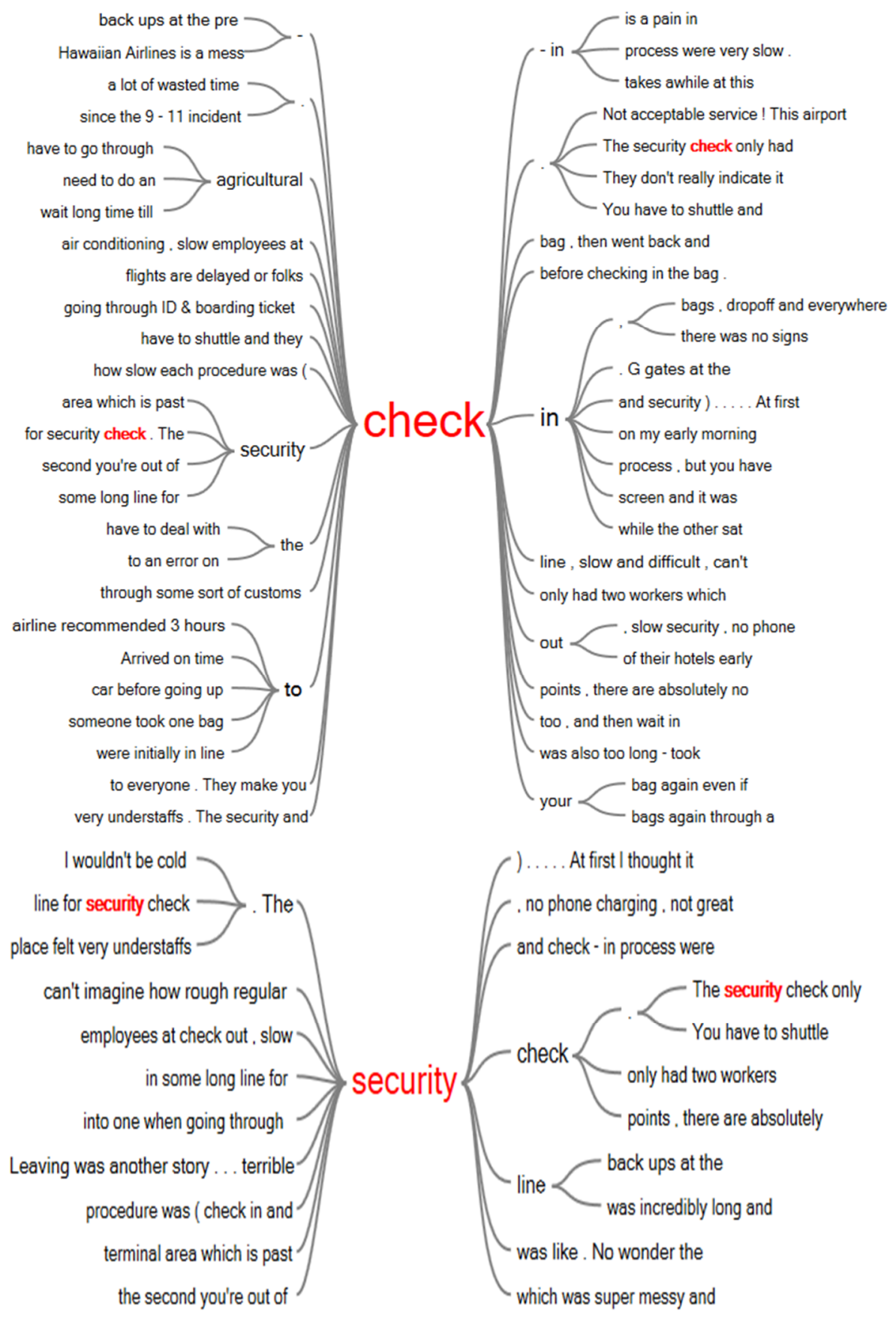

Figure A2. Word Trees "Check" and "Security" for the Dissatisfied Travelers at HIA.

\section{References}

Allen, Jaime, Maria Grazia Bellizzi, Laura Eboli, Carmen Forciniti, and Gabriella Mazzulla. 2020a. Latent factors on the assessment of service quality in an Italian peripheral airport. Transportation Research Procedia 47: 91-98.

Allen, Jaime, Maria Grazia Bellizzi, Laura Eboli, Carmen Forciniti, and Gabriella Mazzulla. 2020b. Service quality in a mid-sized air terminal: A SEM-MIMIC ordinal probit accounting for travel, sociodemographic, and user-type heterogeneity. Journal of Air Transport Management 84: 101780.

Allen, Jaime, Maria Grazia Bellizzi, Laura Eboli, Carmen Forciniti, and Gabriella Mazzulla. 2021. Identifying strategies for improving airport services: Introduction of the Gap-IPA to an Italian airport case study. Transportation Letters 13: 243-53.

Aureli, Selena. 2017. A comparison of content analysis usage and text mining in CSR corporate disclosure. International Journal of Digital Accounting Research 17: 1-32.

Azeem, Muhammad, Naseer Ahmad Salfi, and A. H. Dogar. 2012. Usage of NVivo software for qualitative data analysis. Academic Research International 2: 262-66. 
Bellizzi, Maria Grazia, Laura Eboli, Carmen Forciniti, and Gabriella Mazzulla. 2018. Air Transport Passengers' Satisfaction: An Ordered Logit Model. Transportation Research Procedia 33: 147-54.

Bezerra, George C. L., and Carlos F. Gomes. 2015. The effects of service quality dimensions and passenger characteristics on passenger's overall satisfaction with an airport. Journal of Air Transport Management 44: 77-81.

Bezerra, George Christian Linhares, and Carlos F. Gomes. 2016. Measuring airport service quality: A multidimensional approach. Journal of Air Transport Management 53: 85-93.

Bogicevic, Vanja, Wan Yang, Anil Bilgihan, and Milos Bujisic. 2013. Airport service quality drivers of passenger satisfaction. Tourism Review 68: 3-18. [CrossRef]

Brida, Juan Gabriel, Luis Moreno-Izquierdo, and Sandra Zapata-Aguirre. 2016. Customer perception of service quality: The role of Information and Communication Technologies (ICTs) at airport functional areas. Tourism Management Perspectives 20: 209-16.

Brochado, Ana, Paulo Rita, Cristina Oliveira, and Fernando Oliveira. 2019. Airline passengers' perceptions of service quality: Themes in online reviews. International Journal of Contemporary Hospitality Management 31: 855-73.

Ceccato, Vania, and Stefano Masci. 2017. Airport Environment and Passengers' Satisfaction with Safety. Journal of Applied Security Research 12: 356-73.

Ching, Ming-kei, and Yui Yip Lau. 2016. Travelers' perception on airport satisfaction. Journal of Business E Economic Policy 3: 55-60.

Chuchu, Tinashe. 2017. Destination Marketing: A Study into International Airport Service Experience, Destination Image and Intention to Revisit South Africa. Doctoral dissertation, School of Economic and Business Sciences, University of the Witwatersrand, Johannesburg, South Africa.

Della Corte, Valentina, Mauro Sciarelli, Clelia Cascella, and Giovanna Del Gaudio. 2015. Customer satisfaction in tourist destination: The case of tourism offer in the city of Naples. Journal of Investment and Management 4: 39-50. [CrossRef]

Eboli, Laura, and Gabriella Mazzulla. 2009. An ordinal logistic regression model for analysing airport passenger satisfaction. EuroMed Journal of Business 4: 40-57.

Elias Gonçalves, Max Well, and Mauro Caetano. 2017. Airport level of service: A model according to departing passenger's perceptions at a small-sized airport. Journal of Airline and Airport Management 7: 65-79. [CrossRef]

Fodness, Dale, and Brian Murray. 2007. Passengers' expectations of airport service quality. Journal of Services Marketing 21: $492-506$.

Caballero Galeote, L., and J. Garcia Mestanza. 2020. Qualitative impact analysis of international tourists and residents' perceptions of Málaga-Costa Del Sol Airport. Sustainability 12: 4725. [CrossRef]

Ghazi, Karam, and Salama Ammar. 2018. International tourists' attitudes and satisfaction toward airport F\&B, and duty-free concessions. Journal of Tourism Research 20: 41-65.

Gupta, Rajiv, and Vunnam Venkaiah. 2015. Airport passengers: Their needs and satisfaction. SCMS Journal of Indian Management 12: 46.

Hawaii Tourism Authority. 2019. 2018 Annual Visitor Research Report. Available online: https:/ /www.hawaiitourismauthority.org/ media/4086/2018-annual-report-final-repost-1-7-20.pdf (accessed on 1 July 2020).

Hsieh, Hsiu-Fang, and Sarah E. Shannon. 2005. Three approaches to qualitative content analysis. Qualitative Health Research 15: $1277-88$. [CrossRef]

Jeon, Sunran, and Min-su Kim. 2012. The effect of the servicescape on customers' behavioural intentions in an international airport service environment. Service Business 6: 279-95. [CrossRef]

Kurniawan, Ridha, Samuel Petros Sebhatu, and Sara Davoudi. 2017. Passengers' perspective toward airport service quality (ASQ) (Case study at Soekarno-Hatta International Airport). Journal of the Civil Engineering Forum 3: 21-32. [CrossRef]

Leximancer. 2020. Leximancer User Guide. Leximancer Pty Ltd. Available online: https:/ / doc.leximancer.com/doc/LeximancerManual. pdf (accessed on 1 July 2020).

Liou, James J. H., Ching-Hui Tang, Wen-Chien Yeh, and Chieh-Yuan Tsai. 2011. A decision rules approach for improvement of airport service quality. Expert Systems with Applications 38: 13723-30.

Lupo, Toni. 2015. Fuzzy ServPerf model combined with ELECTRE III to comparatively evaluate service quality of international airports in Sicily. Journal of Air Transport Management 42: 249-59.

Martin-Domingo, Luis, Juan Carlos Martín, and Glen Mandsberg. 2019. Social media as a resource for sentiment analysis of Airport Service Quality (ASQ). Journal of Air Transport Management 78: 106-15. [CrossRef]

Maslen, Richard. 2014. What Role Do Airports Play in Increasing Inbound Tourism? Routes Online. Available online: https:/ /www routesonline.com/news/29/breaking-news/239626/what-role-do-airports-play-in-increasing-inbound-tourism/ (accessed on 1 July 2020).

Matzler, Kurt, and Elmar Sauerwein. 2002. The factor structure of customer satisfaction: An empirical test of the importance grid and the penalty-reward-contrast analysis. International Journal of Service Industry Management 13: 314-32.

Moon, Hyoungeun, Hae Jin Yoon, and Heesup Han. 2017. The effect of airport atmospherics on satisfaction and behavioral intentions: Testing the moderating role of perceived safety. Journal of Travel E Tourism Marketing 34: 749-63.

Oh, Sung-Oun, and Jin-Woo Park. 2014. A study on relative importance and priority regarding airport selection attributes utilizing AHP. International Journal of Business and Social Research 4: 43-53.

Pabedinskaite, Arnoldina, and Viktorija Akstinaite. 2014. Evaluation of the airport service quality. Procedia-Social and Behavioral Sciences 110: 398-409. [CrossRef]

Pandey, Mukesh Mohan. 2016. Evaluating the service quality of airports in Thailand using fuzzy multi-criteria decision making method. Journal of Air Transport Management 57: 241-49. 
Pantouvakis, Angelos, and Maria Francesca Renzi. 2016. Exploring different nationality perceptions of airport service quality. Journal of Air Transport Management 52: 90-98. [CrossRef]

Paramonovs, Sergejs, and Ksenija Ijevleva. 2015. Factor Analysis of Passengers' Satisfaction at "RIGA International Airport". Economics and Business 27: 46-52. [CrossRef]

Prentice, Catherine, and Mariam Kadan. 2019. The role of airport service quality in airport and destination choice. Journal of Retailing and Consumer Services 47: 40-48. [CrossRef]

Rahim, A. Ganiyu. 2016. Perceived service quality and customer loyalty: The mediating effect of passenger satisfaction in the Nigerian airline industry. International Journal of Management and Economics 52: 94-117. [CrossRef]

Richards, Lyn, and Tom Richards. 1994. From Filing Cabinet to Computer. In Analysing Qualitative Data. Edited by Alan Bryman and Robert G. Burgess. London: Routledge, pp. 146-72.

Schuckert, Markus, Xianwei Liu, and Rob Law. 2015. Hospitality and tourism online reviews: Recent trends and future directions. Journal of Travel E Tourism Marketing 32: 608-21.

Skytrax. 2018. World's Top 100 Airports 2018. Skytrax World Airport Awards. Available online: https://www.worldairportawards.com/ worlds-top-100-airports-2018 (accessed on 1 July 2020).

Smith, Andrew E., and Michael S. Humphreys. 2006. Evaluation of unsupervised semantic mapping of natural language with Leximancer concept mapping. Behavior Research Methods 38: 262-79. [CrossRef]

Sotiriadou, Popi, Jessie Brouwers, and Tuan-Anh Le. 2014. Choosing a qualitative data analysis tool: A comparison of NVivo and Leximancer. Annals of Leisure Research 17: 218-34. [CrossRef]

Straker, Karla, and Cara Wrigley. 2018. Engaging passengers across digital channels: An international study of 100 airports. Journal of Hospitality and Tourism Management 34: 82-92. [CrossRef]

Tsai, Wen-Hsien, Wei Hsu, and Wen-Chin Chou. 2011. A gap analysis model for improving airport service quality. Total Quality Management \& Business Excellence 22: 1025-40.

U.S. News \& World Report. 2019. Honolulu Airport Ranked the Third Worst in North America. U.S. News \& World Report. October 8. Available online: https:/ / www.usnews.com/news/us/articles/2019-10-08/honolulu-airport-ranked-third-worst-in-customersatisfaction (accessed on 1 July 2020).

Wattanacharoensil, Walanchalee, Markus Schuckert, Anne Graham, and Alison Dean. 2017. An analysis of the airport experience from an air traveler perspective. Journal of Hospitality and Tourism Management 32: 124-35. [CrossRef]

Yunus, Nor Sara Nadia Muhamad, Jamil Bojei, and Wan Edura Wan Rashid. 2013. Service Quality towards Customer Loyalty in Malaysia's Domestic Low Cost Airline Services. International Journal of e-Education 3: 333.

Zakrzewski, Dorothea. 2008. Assessing Privatized Airport Performance from Stakeholder Viewpoints: A Study of Sydney Airport. Performance Measurement and Management Control: Measuring and Rewarding Performance (Studies in Managerial and Financial Accounting, Vol. 18). Bingley: Emerald Group Publishing Limited, pp. 253-72.

Zhao, Mengyuan. 2019. Passenger Perception of Service Quality of Chinese Airlines and the Impact on Intention to Recommend. Doctoral dissertation, Instituto Superior de Economia e Gestão, Universidade de Lisboa, Lisbon, Portugal. 